\title{
Prevalence of psychosocial problems in children with and without epilepsy: A comparative cross-section study.
}

1. MBBS, MCPS, FCPS (Pediatrics) Assistant Professor Developmenta Pediatrics

The Children Hospital and The Institute of Child Health Multan.

2. MBBS, DCH, FCPS (Pediatrics) Associate Professor Pediatric Endocrinology

The Children Hospital and The Institute of Child Health Multan.

3. MBBS, FCPS

Senior Registrar Developmental Pediatrics

The Children Hospital and

The Institute of Child Health Multan.

4. MBBS

Woman Medical Officer

The Children Hospital and

The Institute of Child Health Multan.

5. MBBS, MCPS

Consultant Pediatrician

Shehnaz Sharif District Head

Quarter

Civil Campus. Multan.

Correspondence Address:

Dr. Erum Afzal

Department of Developmental

Pediatrics

The Children Hospital and

The Institute of Child Health Multan. erumafzal@yahoo.com

Article received on:

25/07/2020

Accepted for publication:

$21 / 09 / 2020$

\section{Erum Afzal' ${ }^{1}$, Waqas Imran Khan ${ }^{2}$, Mohammad Khalid Iqbal ${ }^{3}$, Kausar Aftab ${ }^{4}$, Tanveer Ahmad}

ABSTRACT... Objectives: To compare the prevalence of psychosocial problems in children with and without epilepsy. Study Design: Comparative Cross Sectional study. Settings: The Children's Hospital and The Institute of Child Health Multan (CH \& ICH). Period: July 2019 to December 2019. Material \& Methods: Fifty-nine patients of either gender, $5-12$ years of age, diagnosed as Epilepsy were included in group A. For the group B the patient of same number, age and gender without epilepsy visiting the general outpatient department of the hospital with acute illness were included. The children having known psychiatric disorder, and intellectual disability were excluded. Educational level of parents, socioeconomic status, Time of onset, type, outcome of epilepsy, number of antiepileptic medicines used and EEG findings were noted. Intelligence Quotient of each patient was calculated. A Pediatric Symptom Checklist was used for psychosocial problems in all children. Data was analyzed by using SPSS version 20. Result: Out of 118 patients (59 in group A and 59 in group B), 68\% ( $n=73$ ) were male. Mean age of the participants was 10.2years (st dev. \pm 11.1 ). Patients age ranging between $5-9$ years constituted $32 \%(n=38)$ while $68 \%(n=80)$ were more than 9 to 12 years. Most of the children belonged to low socioeconomic status $66 \%(n=78)$. Educational level of parents was below matric in $67.8 \%(n=80)$ and $32.2 \%(n=38)$ were above matric. In Group A $64.41 \%(n=38)$ patients had generalized tonic clonic type of epilepsy, $28.81 \%(n=17)$ partial/ focal type and $3.39 \%(n=2)$ myoclonic type. In $42 \%(n=52)$ of patient's epilepsy was controlled while in 58\% $(n=7)$ patients it was uncontrolled. Psychosocial problems were detected in $59.3 \%$ $(n=35)$ patients in epileptic group A while in $23.7 \%(n=14)$ in non-epileptic group B. Single use of antiepileptic was important factor causing psychosocial problems in epileptic children. Conclusion: Psychosocial problems are more common in Epileptic children, so psychological evaluation and management must be integral part of their therapy.

Key words: Epilepsy, Intellectual Disability, Psychosocial Problems.

Article Citation: Afzal E, Khan WI, Iqbal MK, Aftab K, Ahmad T. Prevalence of psychosocial problems in children with and without epilepsy: A comparative crosssection study. Professional Med J 2021; 28(4):557-563. https://doi.org/10.29309/TPMJ/2021.28.04.5800

\section{INTRODUCTION}

Epilepsy is the most common neurological disorder in children. Its estimated worldwide prevalence is $0.5-2.2 \% .^{1,2}$ Epilepsy is defined as "two or more seizures occurring at least 24 hours apart unprovoked by any immediate identifiable cause, regardless of antiepileptic management". ${ }^{3}$ The international Classification of Epileptic seizures divide the epileptic seizures into FOCAL (partial) and GENERALIZED seizures. Focal (partial) seizures are further divided into Focal sensory seizures and Focal motor seizures, while generalized seizures are further classified into Tonic clonic seizures, Clonic seizures, Tonic seizures, Myoclonic seizures, Atonic seizures, and epilepsy syndromes. ${ }^{4}$

Children with epilepsy are at higher risk for psychosocial problems like cognitive, emotional and behavioral. Family members especially parents are badly affected by the stress caused by the disease. ${ }^{5}$ Although psychiatric disorders are very frequent in children with epilepsy, these disorders remain undiagnosed and untreated. ${ }^{6,7}$ The reason for these behavioral problems in epileptic patient is may be due to dysfunction of central nervous system, as demonstrated in study. ${ }^{8}$ 
The" Pediatric Symptom Checklist "is a 35-item parent-report scale that has been demonstrated for detection of psychosocial problems (cognitive, emotional and behavioral). ${ }^{9}$ It is established by Jellinek, et al as screening tool for psychological and behavioral problems in children with fair validity and reliability. ${ }^{10}$

Epilepsy has been remained the socially noticeable stigma since the ages, because it is not easy to understand, in spite of improved education and increasing awareness. ${ }^{11}$ It is the one of the conditions which not only affect the person having epilepsy but whole family, this is not only due to physical burden of epilepsy but also because of cognitive and psychiatric problems which an epileptic person suffers. ${ }^{12}$

Psychosocial problems in children may lead to a vicious cycle of poor medication compliance leading to uncontrolled epilepsy and further enhancing psychosocial problems. The aim of this study is to identify the psychosocial problems in children with epilepsy and to compare psychosocial problems in children with and without epilepsy.

\section{MATERIAL \& METHODS}

This comparative cross-sectional study was carried out in outpatient department of $\mathrm{CH} \& \mathrm{ICH}$ Multan from July 2019 to December 2019. In this study we made 2 groups A \& B. Group A included 59 epileptic patients of 5 to 12 years of age, of both gender and presented to Rehabilitation services unit. For the group B we enrolled the patients of same number, age and gender without epilepsy visiting with acute illness (upper respiratory tract infection, gastroenteritis, urinary tr act infection), to the general outpatient department of the hospital. The children of both groups were matched as closely as possible. The children having known psychiatric disorder, refractory epilepsy, and intellectual disability, were excluded.

Parents/guardian were detailed about the study and prior written consent was taken. The study was approved by institutional ethical committee. No conflict of interest was involved in this study. No financial support was provided by the institution or pharmaceutical company. A detailed history was taken from parents/guardian and patients. Complete neurological examination was done in all patients.

Patient was labelled as epileptic when he or she had two or more afebrile seizures occurred at least 24 hours apart unprovoked by any immediate unidentifiable cause regardless of antiepileptic management. Detail of seizures was taken from eye witness of the seizures. EEG of all enrolled cases was carried out from Neurology department. Type of epilepsy was determined by clinical presentation on history and EEG findings.

Cognitions of the patients was also assessed by using Slossen intelligence scale by our psychologist. Patient having intelligence quotient less than 70 were not included in the study. Socio economic status was also assessed by monthly income. Family having monthly income less than 20,000 was labelled as low status, family with monthly income between 20,000 to 50,000 labelled as middle status while the family with monthly income more than 50,000 labelled as high status. Educational level of parents was noted, whether above or below matric. Time of onset of epilepsy was also noted whether onset below 3 years of age or above. Epilepsy control was determined by the fit free time period more than twice of time period with fits. Number of medicines used by patient to control the fits were noted.

For psychosocial problems a" Pediatric Symptom Checklist "was used. This checklist facilitates the recognition of cognitive, emotional and behavioral problems. The checklist contains 35 items that are rated as "Never" "Sometimes" or "Often" scored "0" "1" and "2" respectively. We labelled "Never" if symptom not present ever. We labelled "sometimes" or "often "if symptoms occurred less than or more than 3 times in a weak respectively. The total score is calculated by adding together the score for each of 35 items. The children ages 6 through 16, a cutoff score of 28 or higher indicates psychological impairment. For children ages 4 and 5, cutoff score is 24 or 
higher.

All information was recorded on already designed Performa for final analysis. Data was analyzed by using SPSS version 20. Result was calculated in mean and standard deviation for quantitative data, frequencies and percent for qualitative data. Chi square test was used. A probability value of less than or equal to 0.05 was considered statistically significant. Prevalence ratio (ODDS ratio) with $95 \%$ confidence interval of all variables were calculated.

\section{RESULTS}

Out of 118 patients 59 were in group $A$ and 59 group B. $32 \%(n=45)$ were females and $68 \%(n=73)$ were male.32\% $(n=38)$ patients were age ranges between 5 to 9 years while $68 \%(n=80)$ more than 9 to 12 years, with mean age of 10.2 years (st dev. \pm 11.1$)$ There was no significance between both groups regarding age ( $p$-value $<0.29)$.
Educational level of parents of $67.8 \%(n=80)$ patients was below matric while $32.2 \% \quad(n=38)$ above matric. 66\% $(n=78), 32.3 \%(n-38)$ and $1.7 \%(n=2)$ patients belonged to low, middle and high socioeconomical status respectively(Table-I). Other characteristics are shown in Table-l.

Amongst the group A $64.41 \%(n=38)$ patients had generalized tonic clonic type of epilepsy, $28.81 \%(n=17)$ partial/focal type, $3.39 \%(n=2)$ myoclonic type, while $3.39 \%(n=2)$ were others (Absence, Atonic). Data regarding outcome, Onset of epilepsy, number of medicine used and EEG findings of children of group $A$ are shown in Table-II.

The determinants of psychosocial problems in children with and without epilepsy are shown in Table-III.

The determinants of psychosocial problems in children with epilepsy are shown in Table-IV.

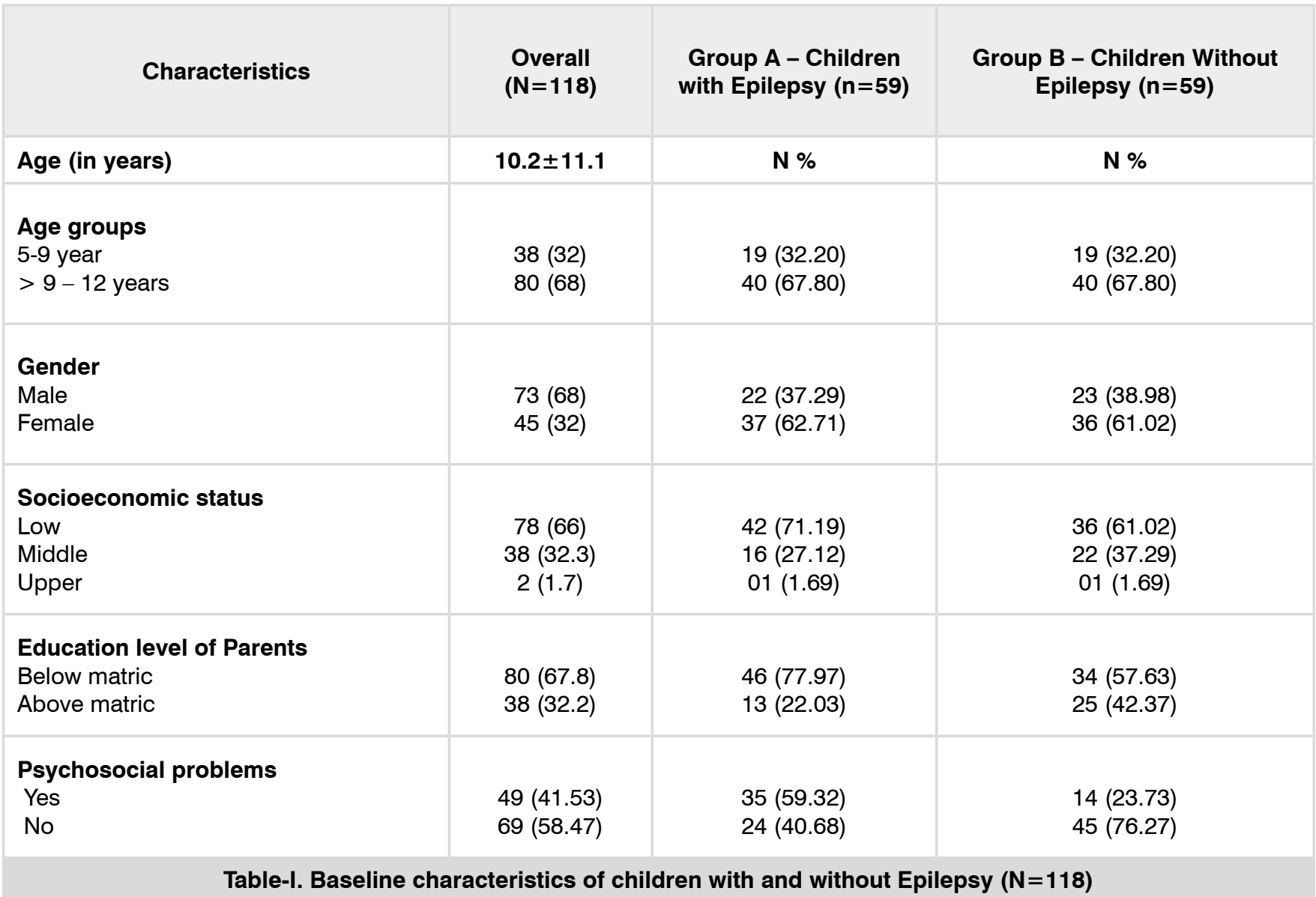




\begin{tabular}{|c|c|}
\hline & $\mathrm{n}, \%$ \\
\hline $\begin{array}{l}\text { Type } \\
\text { G.Tonic clonic } \\
\text { Focal } \\
\text { Myoclonic } \\
\text { Others }\end{array}$ & $\begin{aligned} 38 & (64.41) \\
17 & (28.81) \\
2 & (3.39) \\
2 & (3.39)\end{aligned}$ \\
\hline $\begin{array}{l}\text { Outcome } \\
\text { controlled } \\
\text { uncontrolled }\end{array}$ & $\begin{array}{c}52(88.14) \\
7(11.86)\end{array}$ \\
\hline $\begin{array}{l}\text { Onset } \\
\text { Before 3yrs of age } \\
\text { After } 3 \text { yrs of age }\end{array}$ & $\begin{array}{l}17(28.81) \\
42(71.19)\end{array}$ \\
\hline $\begin{array}{l}\text { No. of medicine used } \\
\text { Single drug } \\
\text { Multiple drugs }\end{array}$ & $\begin{array}{l}41(69.5) \\
18(30.5)\end{array}$ \\
\hline $\begin{array}{l}\text { EEG finding } \\
\text { Positive } \\
\text { Negative }\end{array}$ & $\begin{array}{l}30(50.85) \\
29(49.15)\end{array}$ \\
\hline
\end{tabular}

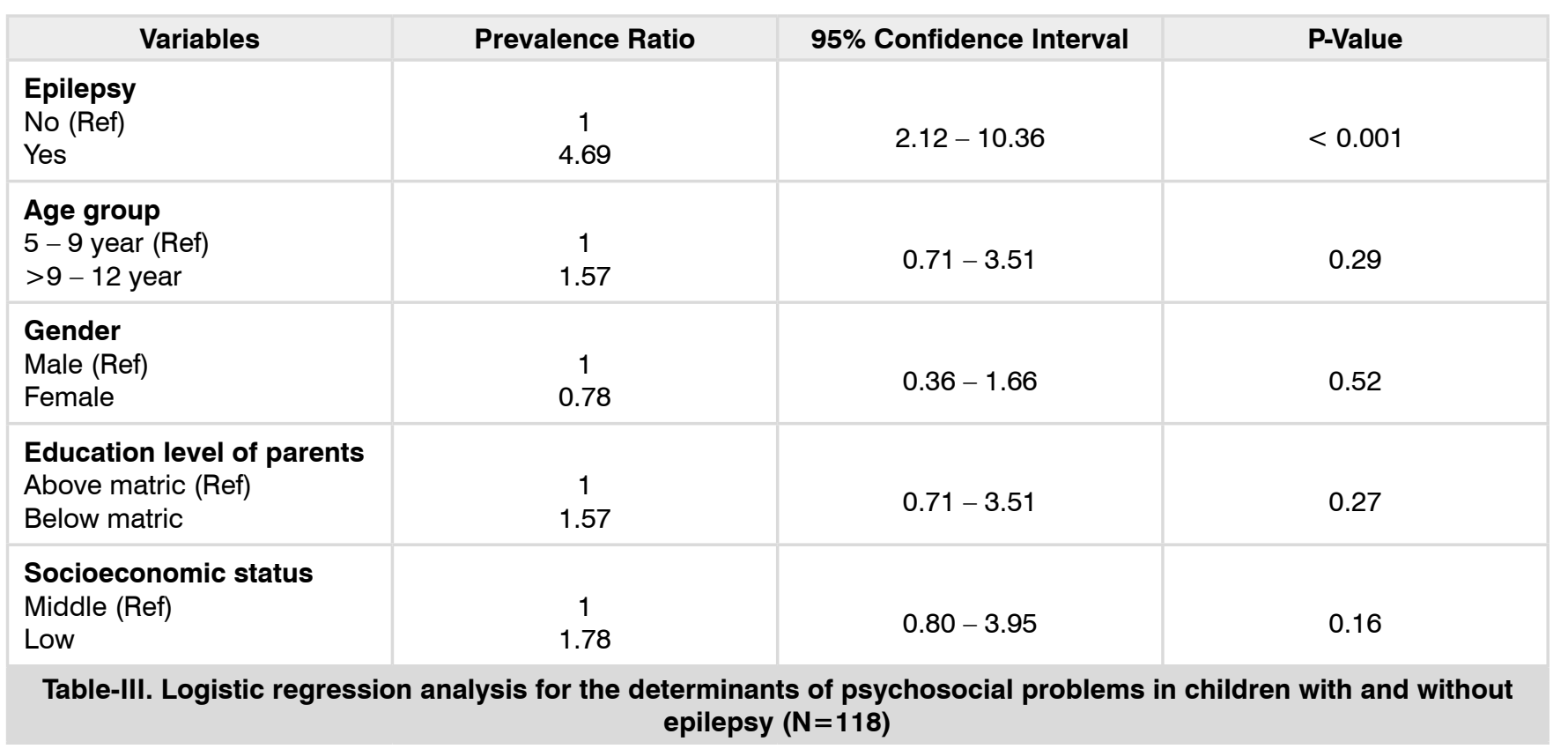

\section{DISSCUSSION}

In the present study we assessed the psychosocial problems in children with epilepsy by using pediatric symptom questionnaire of 35 items. We found that Psychosocial problems were detected in $59.3 \%$ patients in epileptic group while in $23.7 \%$ in non-epileptic children. Epileptic group has 4.96 higher prevalence ratio of psychosocial problems including Cognitive, emotional and behavioral problems as compared to non-epileptic group, which is also statistically significant. These findings are similar to another study conducted by Abdullah Ayidh Almutairi et al at king Abdul Aziz Medical city in Riyadh Saudi Arabia. ${ }^{13}$ Rutter et al also reported the psychiatric problems in children with epilepsy. ${ }^{14}$ Studies done by Davies et $\mathrm{al}^{15}$, Sillanpaa et $\mathrm{al}^{16}$, B Hoie et $\mathrm{al}^{17}$ and Lin JJ, Mula M \& Hermann BP18 RoosRodenburg ${ }^{19}$ reported the same findings. 


\begin{tabular}{|c|c|c|c|}
\hline Variables & Prevalence Ratio & 95\% Confidence Interval & P-Value \\
\hline $\begin{array}{l}\text { Age group } \\
5-9 \text { year } \\
>9-12 \text { year }\end{array}$ & $\begin{array}{c}1 \\
1.09\end{array}$ & $0.36-3.31$ & 0.88 \\
\hline $\begin{array}{l}\text { Gender } \\
\text { Male } \\
\text { Female }\end{array}$ & $\begin{array}{c}1 \\
1.33\end{array}$ & $0.45-3.95$ & 0.60 \\
\hline $\begin{array}{l}\text { Education level of parents } \\
\text { Above matric } \\
\text { Below matric }\end{array}$ & $\begin{array}{c}1 \\
3.0\end{array}$ & $0.84-10.70$ & 0.90 \\
\hline $\begin{array}{l}\text { Socioeconomic status } \\
\text { Middle } \\
\text { Low }\end{array}$ & $\begin{array}{c}1 \\
0.73\end{array}$ & $0.23-2.34$ & 2.33 \\
\hline $\begin{array}{l}\text { EEG result } \\
\text { Normal } \\
\text { Positive }\end{array}$ & $\begin{array}{c}1 \\
1.40\end{array}$ & $0.49-3.98$ & 0.52 \\
\hline $\begin{array}{l}\text { Type of Epilepsy } \\
\text { Others } \\
\text { Generalized Tonic clonic } \\
\text { Partial }\end{array}$ & $\begin{array}{c}1 \\
2.17 \\
0.7\end{array}$ & $\begin{array}{c}0.27-17.27 \\
0.08-6.22\end{array}$ & $\begin{array}{l}0.46 \\
0.75\end{array}$ \\
\hline $\begin{array}{l}\text { Age of onset } \\
>3 \text { years of age } \\
<3 \text { years of age }\end{array}$ & $\begin{array}{c}1 \\
0.73\end{array}$ & $0.23-2.34$ & 0.59 \\
\hline $\begin{array}{l}\text { No of anti-epileptic drugs } \\
\text { Single } \\
\text { Multiple }\end{array}$ & $\begin{array}{c}1 \\
0.30\end{array}$ & $0.09-0.94$ & 0.04 \\
\hline $\begin{array}{l}\text { Epilepsy control } \\
\text { Controlled } \\
\text { Uncontrolled }\end{array}$ & $\begin{array}{c}1 \\
4.75\end{array}$ & $0.53-42.37$ & 0.16 \\
\hline
\end{tabular}

This study reported that the children using multiple antiepileptic drugs showed $70 \%$ protection against psychosocial problems in epileptic children and it is statistically significant. While age of children, gender, socioeconomical status, educational level of parents, age of onset, type of epilepsy, Positive EEG findings and good control of seizures had no significant effect for developing psychosocial problems in epileptic children. A study done by Matti Sillanpää also showed no statistical difference of both sexes to have behavior problems. ${ }^{20}$ Sabaz et al also found no significant relation of psychosocial problems with age at the onset of epilepsy. ${ }^{21}$ While Funda Gökgöz-Durmaz ${ }^{22}$ and $B$ Hoie et al $^{17}$ reported more psychiatric problems in children having generalized type epilepsy. These differences may be due to variations in selection of patients studied in different studies.

The limitation of this study was that we could not compare our findings with more previous ones as there were limited number of previous studies on this topic, study design of our study is different from others previously done, and we selected only uncomplicated epileptics with normal IQ level. Further studies must be carried out on this problem.

\section{CONCLUSION}

Psychosocial problems like cognitive, emotional and behavioral are more common in Epileptic children as compared to non-epileptics. Use of single antiepileptic drug was important factor causing psychosocial problems in epileptic children. So these patients must be referred for 
psychological management along with medical treatment.

\section{Copyright@ 21 Sep, 2020.}

\section{REFERENCES}

1. Dafoulis V, Kalyva E. Factors associated with behavioral problems in children with idiopathic epilepsy. Epilepsy Res 2012; 100:104-112.

2. Ngugi Ak, Bottomley C, KLieinschmidt I, Sander J W, Newton CR. Estimation of the burden of active and life time epilepsy; A meta analytic approach: Estimation on burden of epilepsy. Epilepsia 2010; 51:883-890.

3. Stafstrom CE, Carmant L. "Seizure and epilepsy: An overview for neuroscientists". Cold Spring Harb Perspect Med. 2015 Jun 1; 5(6).

4. Kliegman, Stanton. St Geme. Schor. Seizures in childhood. Nelson text book of pediatrics. 2823-2829.

5. Li Y CY, Qin J, Zhang JX. Parental anxiety and quality of epileptic children. Biomed Environ Sci 2008; 21:228232.

6. Reilly C, Kent E, Neville BGR. Review: Psychopathology in childhood epilepsy. Child and Adolescent Mental Health 2013; 18:65-75.

7. Ott D, Siddarh P, Gurbani S, et al. Behavioral disorders in pediatric epilepsy: Unmet psychiatric need. Epilepsia 2003; 44:591-597.

8. Koleoso $\mathrm{ON}$ and Uwadiae E. "Intellectual function among epileptic children: The role of epilepsy related-factors in Nigeria." IQSR Journal of Humanities and Social Science 16.4[2013]:41-46.

9. Jellinek MS, Murphy JM, Little M, Pagano ME, Comer $\mathrm{DM}$, Kelleher KJ. Use of the pediatric symptom checklist to screen for psychosocial problems I pediatrics primary care: A national feasibility study. Arch Pediatr Adolesc Med.1999; 153(3):254-260.

10. Jellinek MS, et al. "Pediatric symptom checklist: Screening school aged children for psychosocial dysfunction". The journal of pediatrics 12.2(1988):201209.
11. Pastern\& JL. An analysis of social perceptions of epilepsy: Increasing realization as seen through the theories of Comte and Weber. Social Science and Medicine 15E. Oxford: Bergamon Press. 1981:223-9.

12. Macro Mula, Josemil w. sander. Psychosocial aspects of epilepsy: A wider approach. BJPsych Open. 2016 Jul; 2(4): 270-274.

13. Abdullah Ayidh Almutrairi et al. "Psychosocial problems in Children with Idiopathic Epilepsy". EC Neurology 10.2(2018):91-97.

14. Rutter et al. "Neuropsychiatric study in childhood". Philadelphia: J.B.Lippincott[1970].

15. Davies S, Heyman I, Goodman R. (2003) A population survey of mental health problems in children with epilepsy. Dev Med Child Neurol 45: 292-295.

16. Sillanpaa M, Haataja L, Shinnar S. (2004) Perceived impact of childhood-onset epilepsy on quality of life as an adult. Epilepsia 45:971-977.

17. B Høie et al. Psychosocial problems and seizurerelated factors in children with epilepsy. DOI: $10.1017 /$ S001216220600045.

18. Lin JJ, Mula M, Hermann BP. Uncovering the neurobehavioural comorbidities of epilepsy over the lifespan. Lancet 2012; 380: 1180-92. [PMC free article] [PubMed] [Google Scholar].

19. Roos Rodenburg et al. "Psychosocial issues for children with epilepsy". Epilepsy \& Behavior:Volume 22,Issue 1,September 2011.p\# 47-54.

20. M. Sillanpää, J. Helen Cross. "The psychosocial impact of epilepsy in childhood“. Epilepsy \& Behavior 15 (2009) S5-S10.

21. Sabez M, Cairns DR, Lawson JA, Bleared AF, Bye $A M E(2001)$. The health related quality of life of children with refractory epilepsy: A comparison of those with \& without intellectual Disability. Epilepsia42:621-628.

22. Funda Gökgöz-Durmaz', Fatma Gökşin Cihan'1, Meltem Uzun', Ruhuşen Kutlu. "Mental health problems in children with uncomplicated epilepsy; relation with parental anxiety". The Turkish Journal of Pediatrics 2016; 58: 259-265. 


\section{AUTHORSHIP AND CONTRIBUTION DECLARATION}

\begin{tabular}{|c|c|c|c|}
\hline Sr. \# & Author(s) Full Name & Contribution to the paper & Author(s) Signature \\
\hline 1 & Erum Afzal & $\begin{array}{l}\text { Literature Search, Study design, } \\
\text { Resutls, Discussion, Final } \\
\text { approval. }\end{array}$ & Guntfind \\
\hline 2 & Waqas Imran Khan & $\begin{array}{l}\text { Data acquisition, Analysis of } \\
\text { interpretation \& final approval. }\end{array}$ & \\
\hline 3 & M. Khalid Iqbal & $\begin{array}{l}\text { Data acquisistion of } \\
\text { interpretationof final approval. }\end{array}$ & \\
\hline 4 & Kausar Aftab & $\begin{array}{l}\text { Introduction, Results, Discussion } \\
\text { \& Final approval. }\end{array}$ & \\
\hline 5 & Tanveer Ahmad & $\begin{array}{l}\text { Introduction, Results, } \\
\text { Discussion, Final approval. }\end{array}$ & \\
\hline
\end{tabular}

